\title{
Construcciones de la identidad femenina desde el género y la negritud: una aproximación al análisis de cuatro revistas académicas
}

MSc. Marybel Soto Ramírezi, Universidad Nacional

Recibido: $12 / 6 / 2014$

Aceptado: 24/9/2014

\section{Resumen}

Este artículo analiza cuatro revistas académicas dedicadas a los estudios de las mujeres. El objetivo de la aproximación es identificar construcciones de la identidad femenina desde el género y negritud. Se intenta mostrar otra mirada que problematice la subordinación femenina, la opresión, la "racialización" de la categoría género así como las formas de producción y circulación del conocimiento como acercamiento más propicio para abordar la heterogeneidad del colectivo "mujeres".

\section{Abstract}

Female identity constructs from the perspective of gender and negritude: an approach to the analysis of four academic journals

This paper is based upon the analysis of four academic journals devoted to studies on women's issues. The purpose of this approach is, based upon a general analysis of several academic journals, identify the construction of the female identity from the perspectives of genre and negritude. The aim of this analysis is to take a different look from the view of otherness which problematizes female subordination, the oppression, the stigmatization of the genre category based on racial issues, as well as the ways of producing and circulating knowledge as a more appropriate approach to touch upon the heterogeneity of women as a whole.

El movimiento de mujeres ha teorizado su praxis y ha construido una epistemología desde el feminismo, con categorías propias de análisis, para tratar de explicar la situación de subordinación femenina. Sin embargo, es interesante ver que en su lucha por salir de su relación con lo masculino, el feminismo homogeneizó las diferencias

i Licenciada y Máster en Estudios Latinoamericanos por la Universidad Nacional. Estudiante del Doctorado en Estudios Latinoamericanos con énfasis en Pensamiento Latinoamericano. Académica investigadora en el Instituto de Estudios Latinoamericanos de la UNA, donde coordina el Programa Integrado Repertorio Americano.
Marybel Soto Ramírez. Construcciones de la identidad femenina desde el género y la negritud: una aproximación al análisis de cuatro revistas académicas. Revista Comunicación. Año 35, vol. 23, núm. 2, juliodiciembre, 2014. Tecnológico de Costa Rica. ISSN Impresa 0379-3974/ e-ISNN 1659-3820

PALABRAS CLAVE:

Pensamiento decolonial, pensamiento desde las mujeres, género, negritud, identidades, revistas académicas.

KEY WORDS:

Decolonial thinking, thought from the view of women, gender, negritude, identities, academic journals. 
Revistas feministas analizadas

\begin{tabular}{|c|c|c|c|c|c|}
\hline $\begin{array}{c}\text { NOMBRE DE LA } \\
\text { REVISTA }\end{array}$ & PAÍS & $\begin{array}{l}\text { PUBLICADA } \\
\text { POR }\end{array}$ & SOPORTE & $\begin{array}{l}\text { NÚMEROS } \\
\text { PUBLICADOS }\end{array}$ & ORIENTACIÓN \\
\hline Casa de la mujer & Costa Rica & $\begin{array}{l}\text { Instituto de } \\
\text { Estudios de las } \\
\text { Mujeres } \\
\text { Universidad } \\
\text { Nacional }\end{array}$ & $\begin{array}{c}\text { Papel en los } \\
\text { primeros } \\
\text { números } \\
\text { Digital de } 2004 \text { a } \\
\text { la fecha }\end{array}$ & 15 & $\begin{array}{l}\text { Feminismo } \\
\text { académico }\end{array}$ \\
\hline $\begin{array}{l}\text { S \& F } \\
\text { The Scholar and } \\
\text { Feminist }\end{array}$ & $\begin{array}{c}\text { Estados Unidos } \\
\text { (New York) }\end{array}$ & $\begin{array}{c}\text { The Barnard Cen- } \\
\text { ter for Reseach } \\
\text { on Women }\end{array}$ & Digital & 11 & $\begin{array}{l}\text { Feminismo } \\
\text { académico }\end{array}$ \\
\hline Lolas & Alemania & LOLA PRESS & Papel y Digital & 23 & $\begin{array}{l}\text { Debate feminista, } \\
\text { feminismos y } \\
\text { subalternidad }\end{array}$ \\
\hline $\begin{array}{l}\text { Actualidad } \\
\text { Etnica.com }\end{array}$ & Colombia & $\begin{array}{c}\text { Fundación Akina } \\
\text { Zaji Sauda } \\
\text { (Conexión de } \\
\text { mujeres negras } \\
\text { de Colombia) }\end{array}$ & Digital & 4 & $\begin{array}{l}\text { Comunicación } \\
\text { interétnica e in- } \\
\text { tercultural que } \\
\text { incluye debate } \\
\text { feminista } \\
\text { (afrocolombianas } \\
\text { Indígenas, mesti- } \\
\text { zos, raizales) }\end{array}$ \\
\hline
\end{tabular}

Hoy, los feminismos teóricos y de base han cuestionado esa construcción de mujer que subsume categorialmente las diferencias y la heterogeneidad de las féminas del mundo. Entonces, al señalar el etnocentrismo del feminismo hegemónico, se reivindican las necesidades, vivencias y experiencias específicas de la diversidad de las mujeres para lograr un diálogo inclusivo, democratizante y descolonizador. Al mismo tiempo, se propone como imprescindible para el análisis, la interseccionalidad de la categoría género con otras categorías sociales, como clase social, raza, etnia, orientación sexual, etc.

El diseño de esta aproximación se sostiene en la investigación basada en cuatro revistas especializadas en análisis feminista o con análisis feminista en su contenido: Casa de la Mujer, de Costa Rica, S \& F The Schoolar Feminist, de Estados Unidos, Lolas, de Alemania y Actualidad Étnica, de Colombia. La selección de esas revistas se dio a partir del interés por indagar las propuestas sobre la identidad femenina que revistas académicas incluyen sobre la interseccionalidad de género y negritud, principalmente con base en los feminismos poscoloniales y los estudios de la subalternidad. Además, se consideraron los siguientes criterios generales:
- clara identificación como revistas de debate feminista,

- inclusión de análisis de la construcción de la identidad femenina $y$

- incorporación al debate de planteamientos de los Ilamados feminismos poscoloniales.

De igual modo, se juzgó interesante que las revistas fueran pertenecientes a diferentes países.

El análisis hecho se fundamenta en las afirmaciones de Pita (2013) quien plantea que las revistas no solo son fuentes documentales sino también objetos de estudio y por tanto, el análisis de sus características físicas resulta importante en sí mismas pues, aporta integralmente, al análisis de los contenidos. En este caso, al menos son criterios fundamentales para conformar un perfil el número de publicaciones, la casa editorial y la orientación de la revista. Las revistas estudiadas y sus características básicas generales se detallan en el siguiente cuadro:

Además, se registró que los contenidos incorporados por las revistas elegidas estuvieran relacionados con temas como feminismo poscolonial, de la negritud y de lo indígena. El fin es estudiar propuestas de construcciones 
de la identidad femenina desde el género y la negritud como crítica al feminismo hegemónico. De cada una de las revistas seleccionadas se lograron identificar dos artículos, en algunos casos de una misma autora, en otros de autoras diferentes.

La relación de artículos analizados según revista por autora, se muestra en el siguiente cuadro.

El hecho de que las autoras fueran también académicas resultó beneficioso para este trabajo, pues su discurso es letrado y se orienta a un público informado, conocedor de las temáticas citadas, con cercanía al marco teórico conceptual utilizado por la teoría de género para construir sus desarrollos epistemológicos.

Es importante hacer notar que las revistas elegidas son todas de teoría y pensamiento feminista y por tanto, clasificables como revistas especializadas. Ello implica que están dirigidas a sectores específicos de la academia.

Asimismo, vale la pena resaltar que todos estos productos editoriales incluyen artículos bien informados, que proponen una construcción de la identidad teorizando sobre ello, es decir, construyendo pensamiento. Todas, excepto Actualidad Étnica, consideran a su re- ceptor como un público educado, con niveles de formación en educación superior. Valga indicar que en el universo de las revistas académicas y especializadas, hay sesgo en las cartografías del conocimiento, que solo toman en consideración los saberes académicos y muy escasamente, o en ningún grado, los saberes populares sobre construcción de las identidades. Sería interesante una valoración desde las bases a partir de los sincretismos culturales y religiosos y la feminidad. Quede este tema sugerido para una investigación futura.

Antes de avanzar en el análisis de los contenidos y propuestas de los artículos sobre construcciones de identidad femenina según la propuesta que nos guía, es imprescindible realizar algunas precisiones conceptuales para una mejor comprensión de la propuesta. En primera instancia, en este artículo "negritud" atañe a un concepto de reivindicación identitaria, donde los negros y su cultura, se reconocen y reafirman a sí mismos desde la colonialidad del ser y del saber que postula el pensamiento decolonial y los estudios subalternos. Al identificar el locus de enunciación, estas personas se reconocen desde la herida colonial que ha marcado las vidas de todas las personas del Ilamado Tercer Mundo con geopolíticas del conocimiento, excluyentes, sexistas y opresoras.

Cuadro 2

Relación de artículos, según revista y autora

\begin{tabular}{|c|c|c|}
\hline NOMBRE DE LA REVISTA & NOMBRE DEL ARTíCULO & AUTORA \\
\hline $\begin{array}{c}\text { LOLA PRESS Revista Feminista } \\
\text { Internacional }\end{array}$ & Género y racismo & Maitse Teboho \\
\hline $\begin{array}{c}\text { LOLA PRESS Revista Feminista } \\
\text { Internacional }\end{array}$ & Ennegrecer el feminismo & Sueli Carneiro \\
\hline S\&F Online & $\begin{array}{c}\text { Rewriting Dispersal: Africana } \\
\text { Gender Studies }\end{array}$ & Kaisha-Kahan Y. Perry \\
\hline S\&F Online & $\begin{array}{c}\text { The Growding with my Sisters: } \\
\text { Toward a Black Diasporic Feminist } \\
\text { Agenda in Las Américas }\end{array}$ & Kaisha Kahan Y. Perry \\
\hline Casa de la mujer & $\begin{array}{c}\text { La identidad de género: una } \\
\text { reflexión desde las ciencias sociales } \\
\text { Lo visible y lo invisible: la } \\
\text { participación política de las mujeres } \\
\text { y las minorías étnicas }\end{array}$ & Nilsen Pérez \\
\hline Actualidad étnica & $\begin{array}{c}\text { Identidades desgarradas: las } \\
\text { mujeres negras de Colombia } \\
\text { Mujeres negras de Colombia: } \\
\text { sirvientas, putas y matronas. } \\
\text { Aproximación a la mujer negra de } \\
\text { Colombia }\end{array}$ & Betty Ruth Lozano \\
\hline
\end{tabular}




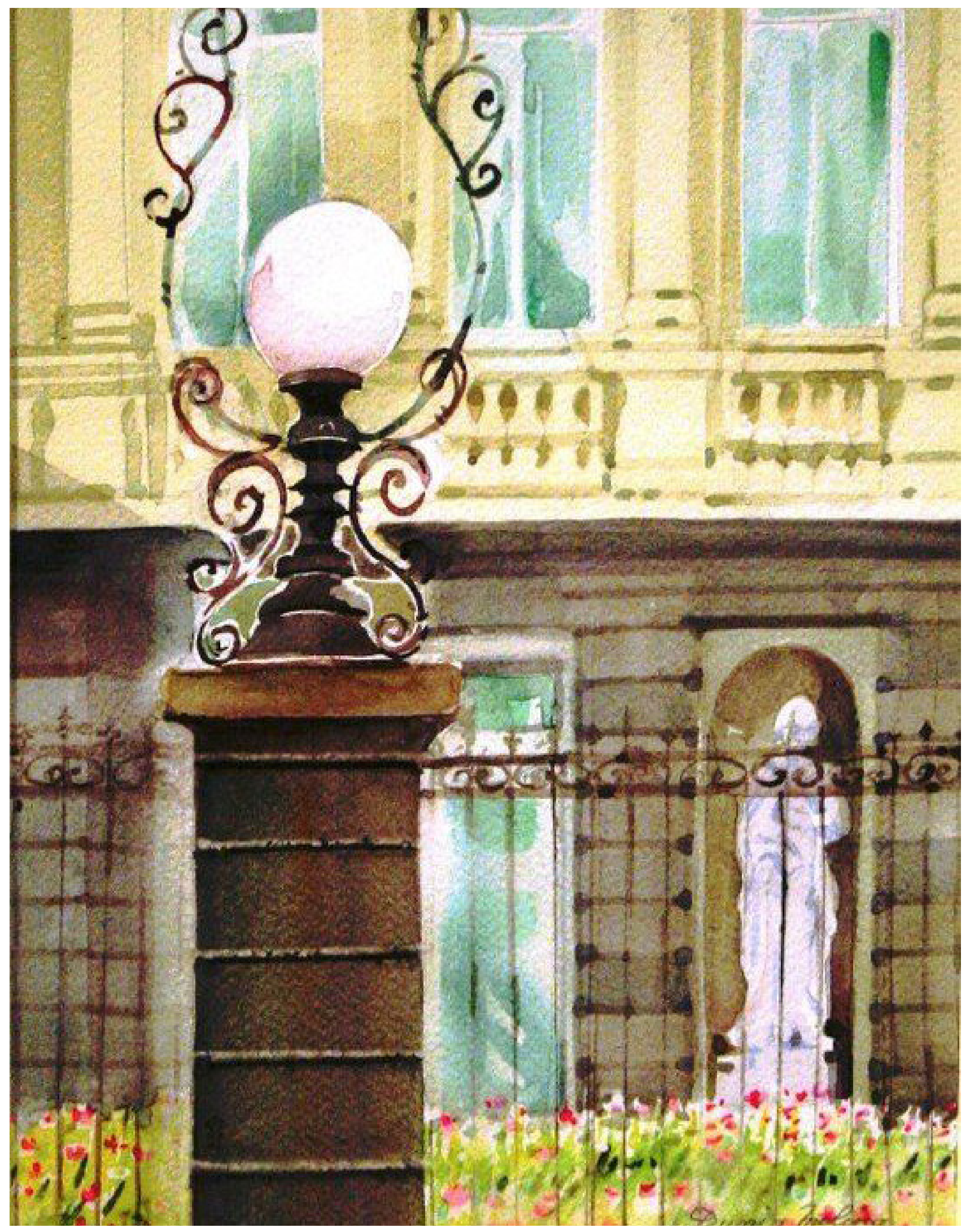

Dunia Molina M. 
"Raza" se comprende en la dimensión problemática del concepto, como un constructo social, al igual que el género. Por ello, más allá de una configuración fenotípica y del color de piel, el término remite a la forma como la colonialidad ha dividido estratificadamente el mundo y ha organizado socialmente el trabajo. La idea de raza también debe tomarse en cuenta como una de las formas en que algunas mujeres experimentan la opresión de género, determinada por la interseccionalidad de esta con la clase y género (Lugones, 2008).

Finalmente, el concepto de "interseccionalidad", desarrollado por N. Crenshaw en 1989, ha venido cobrando gran fuerza para el análisis teórico y metodológico. En lo fundamental, se trata de la intersección del género con otras categorías consideradas mutuamente constituyentes entre sí y cuyo soslayo genera invisibilización, violencias o sesgo epistémicos. Un ejemplo lo presenta Lugones: "la exclusión histórica de mujeres no-blancas en las luchas liberatorias llevadas a cabo en nombre de la Mujer" (2008, p. 77).

\section{ACERCARSE A LOS CONTENIDOS: ¿NO SOY YO UNA MUJER?}

Las identidades, son construcciones sociales y culturales que han pasado a considerarse consustanciales de las personas y por tanto, naturales a ellas. El feminismo hoy habla de "mujeres" como categoría y de "movimiento amplio de mujeres" en la construcción de la praxis política. De todas formas, en ambos casos, refiere a la heterogeneidad que implica todo movimiento social que permite la inclusión de otros discursos y otras prácticas, desde el feminismo mismo, para entender las interseccionalidad que mejor explican la subordinación femenina, la opresión y las dificultades.

En este orden de asuntos, vale la pena rescatar la anéctodota de Sojourner Truth, una mujer negra y esclava, en el Estados Unidos de 1851. En cierta ocasión, ofreció un discurso en Akron, Ohio, donde señalaba que los hombres blancos decían que la mujer merecía consideraciones en virtud de su fragilidad femenina. Sin embargo, en ese transgresor discurso (que aún hoy nos sorprende), Truth reivindica con total claridad su condición de mujer y también de negra, al señalar las múltiples diferencias que la separaban a ella de aquella a quien los hombres definían como "la mujer", frágil, dependiente y por supuesto, blanca:

¿No soy yo una mujer? Porque a mí nunca nadie me ha ayudado con nada: nunca me han cedido el lugar, nunca me han ayudado a llevar cosas pesadas, ni a subir a un carruaje. Miren mis brazos: yo he segado y plantado, he recogido los granos y a mí ningún hombre me ha ayudado. Puedo trabajar tanto y comer tanto como un hombre, cuando se puede iy puedo llevar riata también! He concebido 13 hijos y a todos los he visto vendidos en esclavitud y cuando lloré por ellos mi duelo de madre, nadie, sino Jesús, escuchó mi llanto ¿ No soy yo una mujer? (www.feminist.com¹).

Esta declaración de Ms. Truth ponía -tempranamente- en el tapete de la discusión, un grito de reinvidicación de la mujer negra hacia los hombres blancos, los hombres negros y las mujeres blancas. Vemos cómo subsumir a las mujeres en un solo sujeto (mujer) es un error que salta a pedazos ante nuestra vista: no es posible presuponer que las mujeres blancas, por su condición de mujeres pudieran haber sido solidarias hacia sus congéneres negras. Ellas, al igual que los hombres blancos, no las vieron como mujeres. Más bien se evidencia que las mujeres blancas en realidad han requerido de las mujeres negras, oprimidas, esclavizadas, para mantener ellas un estatus de feminidad y de mujer con poder.

La esclavitud fue un proceso de cosificación de seres humanos convertidos en mercancía. Las mujeres negras además, fueron bestializadas y se les definió como hembras pero se les negó el estatuto de feminidad en comparación con las mujeres blancas. Ante esto, las mujeres negras fueron objeto de todos los abusos posibles, desde la explotación de su trabajo, hasta la sexual y la de su vientre.

La perspectiva de género entonces, no solo permite entender la construcción de lo femenino y lo masculino, sino que también facilita distinguir a las mujeres como grupo social diverso, heterogéneo, susceptible de procesos de deconstrucción de las prácticas discursivas. Por eso, incluir esta perspectiva en análisis como los que se hacen aquí permite integrar otras circunstancias y condiciones que experimentan las mujeres en su diferencia y en su heterogeneidad.

\section{MUJER Y NEGRA: PRECISIONES PARA UNA CONCIENCIA DE SÍ}

La pregunta por la identidad remite al ser, pero no abstraído, sino en relación con el otro o los otros y con su circunstancia. Esa circunstancia, en el caso de las mujeres negras, históricamente, ha sido la de la opresión del patriarcado, la de los amos blancos, la de los varones negros y la de las mujeres blancas: cuatro vértices que atraviesan, -interseccionan- en la categoría mujer negra. 
Si se considera la triple opresión por género, clase y raza que pende sobre la construcción de la identidad de las mujeres negras, es posible afirmar que su identidad se construye desde la feminidad y desde la negritud como identidades fragmentadas, como nos dice la feminista y política costarricense Epsy Campbell:

...una defiende siempre la identidad que más le duele (la identidad femenina) es una identidad lastimada por la sociedad. Cuando una se identifica desde la identidad afro costarricense no es porque estás reivindicando en general que te reconozcan, sino porque es una identidad lastimada, discriminada, menospreciada (...). Muchas de nosotras optamos por reivindicar que somos mujeres afro costarricenses" (Pulgares Caro, 2009, p. 39).

Desde la negritud, las mujeres tratan, en primera instancia, de reivindicar su condición étnica y de raza y por eso, la visibilización es una forma de rescate de la memoria histórica, en estados donde los procesos de construcción de lo nacional han dejado de lado el aporte económico, social y cultural de los grupos afroamericanos, en especial de las mujeres.

Ahora bien, debe reflexionarse que durante los procesos de conquista, como bien nos informa Carneiro (2002) el momento emblemático de sojuzgamiento es la apropiación sexual de las mujeres del grupo derrotado, como afirmación de la superioridad del grupo vencedor. Por ello, la mujer negra ha sido vista como objeto de placer, pero también fue definida como lasciva y utilizada para la procreación de chatel, ${ }^{2}$ ya fuera para el amo o para la venta. En otras palabras, fue sistemáticamente ultrajada. Contrastada con la mujer blanca y definida también en oposición a la fragilidad, virginidad y pureza de esta, le crió sus hijos, se los amamantó, le atendió la casa y en no pocas oportunidades, sirvió al "desahogo" erótico del amo, cuando la religiosidad de la esposa blanca no le permitía mayor expresión sexual que aquella con fines procreativos.

Por eso la pregunta de Sojourner Truth, en 1851, resulta profundamente política y nos sitúa de una forma muy precisa en el debate de los feminismos poscoloniales: al cuestionarse su ser, al ver su identidad femenina desde el espejo de la mujer blanca, se están señalando abiertamente las diferencias de género y de raza, las cuales no pueden ser explicadas sino a partir de la intersección de dichas categorías.
Es por ello que las mujeres en los feminismos de la negritud se reivindican y resisten, junto con su identidad de género y su identidad racial, lo políticamente correcto:

Nós, mulheres negras estamos nas ruas para denunciar e combater o racismo e o sexismo estamos realfirmando a trajetoria de luta de nossas ancestrais, mulheres que foram arrancadas de suas familias, sociedades, culturas, modos de viver na Africa, mulheres que criaram un modo de vida neste continente chamado América (Perry, 2009, p. 1).

La violencia y el abuso hacia las mujeres negras, la violación sistemática de sus cuerpos por parte de los blancos "está en todo origen de todas las construcciones de nuestra identidad nacional (...) y cimiento de todas las jerarquías de género y raza presentes en nuestras sociedades" (Carneiro, 2002, p. 2). Por ello, hay que deconstruir los imaginarios sociales donde pervive la idea de la mulata, de la democracia racial, del romance entre la mujer negra y el blanco y del erotismo que ella y su cuerpo presuponen.

Según los feminismos poscoloniales, la identidad femenina de las mujeres negras se construye a partir de esta consciencia de sí, de que el discurso femenino no ha recogido la particularidad de sus experiencias de vida, que la opresión sobre ellas es distinta a la que han experimentado las mujeres blancas y que las jerarquizaciones y exclusiones del presente tienen anclaje en el pasado; es decir, que aún hoy, género y raza, tienen impacto en la forma de organización de las sociedades latinoamericanas.

Por eso es que Carneiro (2001) es fundamental para entender estos procesos de construcción de la identidad femenina desde la negritud a partir de una conciencia engenderizada y racializada. Carneiro expone que:

...somos parte de un contingente de mujeres que trabajó durante siglos como esclavas labrando la tierra, o en las calles como vendedoras o prostitutas ¡mujeres que no entendían nada cuando las feministas decían que las mujeres debían ganar las calles y trabajar! Somos parte de un contingente de mujeres con identidad objeto. Ayer al servicio de frágiles señoritas...hoy empleadas domésticas de las mujeres liberadas (p. 18).

En este entorno, no puede olvidarse también la necesidad de comprender la identidad femenina desde la 


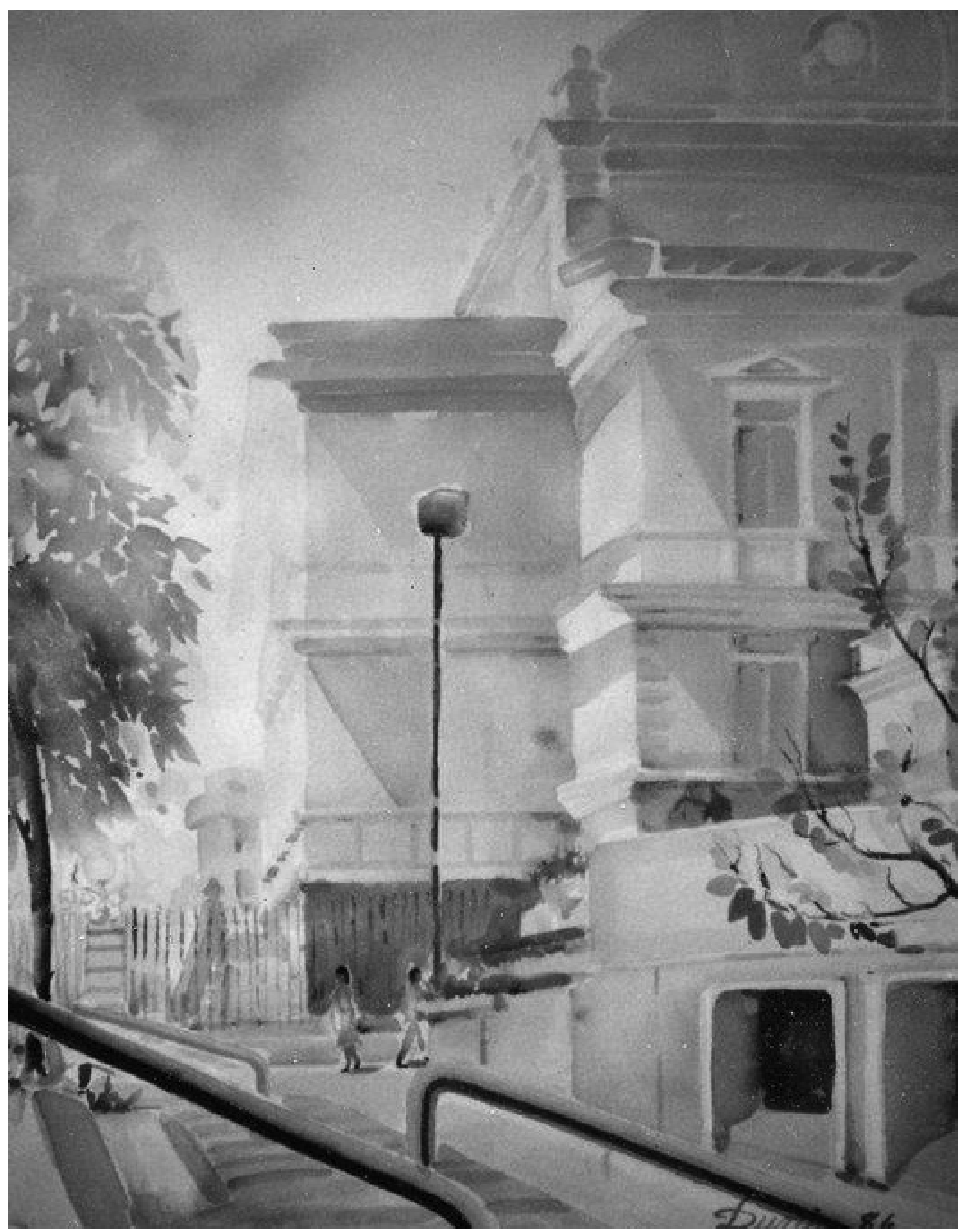

Dunia Molina M. 
negritud, que presupone la conformación de una agenda feminista de la diáspora negra, desde lo que se denomina feminismo negro transnacional.

Por su parte, S\&F Scholar and Feminist (2009) informa sobre las condiciones socioeconómicas de las mujeres negras latinoamericanas de hoy, y apunta a la realidad de que siguen siendo un grupo explotado y olvidado; con la calidad de vida más pobre y los índices de supervivencia más bajos, según los índices de desarrollo humano. Los artículos sobre construcción identitaria de esta revista señalan que es precisamente esa condición deprimida de clase, lo que une a las mujeres negras de América:

Black women in Brazil, Colombia, Nicaragua and elsewhere in the Americas share similar life experiencias with raciscm, sexismo, classism and homophobia -all of which have led to shared policial interest... they mean to affirm a collective empowermente and to convey the urgency of political action both locally and globally (Perry, p. 1).

Según esta autora, la identidad de las mujeres negras americanas se construye por el compartir una experiencia de vida y una lucha política contra el racismo y el sexismo.

¿Qué significa ser mujer y negra en un contexto de opresión y subordinación, invisibilización y otredad? Las teóricas de los feminismos poscoloniales, plantean que el género debe considerarse una variable teórica más, que no puede ser separada de otras categorías de raza y clase, interseccionalidades por las cuales solo es posible entender la opresión de género en las mujeres no blancas.

Desde estas interseccionalidades se puede dimensionar que se es mujer en una sociedad patriarcal; negra, en una sociedad discriminatoria; feminista del tercer mundo, en una corriente de feminismo occidental y hegemónico.

Por tanto, los feminismos de la negritud articulan los ejes de racismo y sexismo en relación con el género, lo cual implica, precisamente, la puesta en marcha de esta nueva agenda política feminista y negra en la construcción identitaria con una tarea política urgente: racializar el feminismo hegemónico occidental. Como dice Perry: "...a firm defense of experience as a basis for forging group identity and organizing politics on all levels (...) and the assertion that Black women who tend to occupy the margins do not question the validity of their experience" $(2009$, p. 4), y que por medio de la solidaridad y la movilización política se construyan la identidad política con perspectiva de género desde la negritud.

\section{CONSTRUIR LA IDENTIDAD FEMENINA LATINOAMERICANA A PARTIR DEL GÉNERO Y LA NEGRITUD: PUNTOS DE PARTIDA A MANERA DE CIERRE}

En primer lugar, las autoras de las revistas seleccionadas concuerdan en proponer que las categorías género y mujer no debe subsumir las experiencias y diferencias de las mujeres. Ellas reivindican y señalan la importancia de que el feminismo abra diálogos y fomente la discusión desde las diferentes posturas y enfoques teóricos, a fin de evitar las posiciones de poder en las agendas políticas feministas. En la actualidad, ellas se encuentran realizando un invaluable aporte, tanto político como metodológico, a partir de las críticas a lo que han denominado transnacionalización y exclusión de necesidades y particularidades.

Ese acto de reconocimiento del legado histórico y de la resistencia en rebeldía, viene a ser una afirmación política, ya que se ha querido ocultar y sacar de la historia oficial de la construcción de la nacionalidad, en particular con los grupos de mujeres negras o afrodescendientes. Ellas están estableciendo sus propias redes y ejerciendo políticamente la reivindicación de sus diversidades y especificidades, señalando las contradicciones del feminismo hegemónico, como afirma Perry: "When the experiences of women from subordinate groups is obscured, denied, excluded from public discourse to foreground experience, it might be a necessary political act" $(2009$, p. 9).

En segundo lugar, hay que reconocer la consciencia interconectada de las categorías raza, género y clase. Ninguna de estas categorías, como nos indica Lugones (2008), puede ni debe separarse, a fin de dimensionar la pervivencia de la colonialidad del ser y del saber y de las geopolíticas del conocimiento. Esta consciencia crece entre las feministas negras, al menos como dan cuenta de ello los artículos de las revistas elegidas, aunque debe signarse claramente, que se trata en todo caso de corrientes de feminismo académico ${ }^{3}$.

En tercer y último lugar, el retar las imágenes estereotipo que encasillan a las mujeres negras siempre en roles subalternos o erotizados, y abogar por la creación de un movimiento de solidaridad transnacional feminista y negro a la vez, se logra un trabajo de calidad en la 
recuperación de la memoria histórica y en la incidencia política. Pérez (2009) así lo sugiere cuando analiza la participación política por cuotas de las mujeres negras en la política costarricense, a partir de la negociación de agendas políticas. Así lo recoge al citar las palabras de Epsy Campbell: "Yo creo en una democracia intercultural y paritaria, y los temas culturales pasan por lo étnico y lo racial" (p. 41).

La identidad de las mujeres negras, como hemos visto, se ha fijado desde el racismo y el sexismo dominante que las homogeneiza. Sin embargo, esta historia compartida no las funde en una sola identidad, antes bien, permite mirarlas en los muchos rostros que conforman su pluralidad. Esta identidad de las mujeres negras (como toda identidad), está en permanente construcción. Por ello, la discusión, el análisis y la reflexión sobre la construcción de las identidades de las mujeres desde el género y la negritud, abrazan las categorías interseccionadas de género, clase y raza y hacen posible dimensionar las aristas que engloba el concepto y la praxis sobre la construcción de las (s) identidad (es) femenina (s) desde el género y la negritud.

Más aún, las propuestas enuncian, desde un locus fijado en lo radical y lo político, que el feminismo occidental y hegemónico no las puede representar ni explicar en sus construcciones identitarias, porque simplemente, no han tomado en cuenta la especificidad de sus experiencias vividas.

La articulación de un pensamiento feminista transcultural deberá incluir estas cuestiones sobre identidad racializada y engenderizada, a partir de los ejes de poder, dominación y opresión patriarcal y racial. ¿De qué otra forma puede construirse la identidad de las mujeres negras sino en solidaridad y hermandad con otras mujeres negras?

Desde mi mirada, solo puedo concluir en que es necesario llenar de contenidos otros las categorías de análisis con que nos acercamos a explicar para teorizar sobre la subordinación femenina. Estos contenidos otros parten desde las perspectivas de las mujeres negras y es lo que se está tratando de construir en la actualidad: un feminismo negro transnacional con la negociación de su agenda política. De ahí que los criterios de marginalidad, exclusión, diferencia cultural, rebeldía y resistencia, estén aunándose con los de género, subordinación y opresión para poder dimensionar, ya no explicar, la construcción de las identidades femeninas de las mujeres negras.

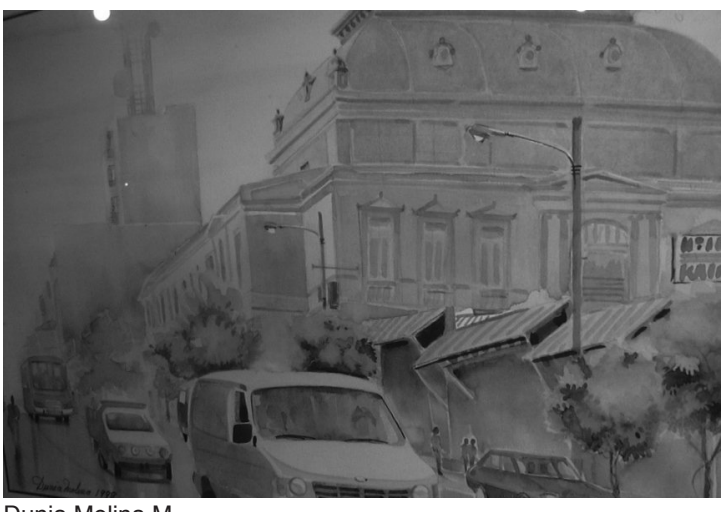

NOTAS

1 La traducción es mía.

2 Chatel es un término en inglés que refiere a los hijos bastardos del amo y la esclava que eran enviados, por lo general, al servicio doméstico de la Casa Grande o vendidos a otras casas, pero siempre para labor de servidumbre. Supuestamente, el aclaramiento de la piel por el mestizaje les otorgaba una suavidad en el carácter y una mejor "presencia" ante los ojos de los blancos.

3 Habría que estudiar más a fondo las relaciones transnacionales de las mujeres negras de base.

\section{REFERENCIAS BIBLIOGRÁFICAS}

Anzaldúa, G. (2008). Fronteras: la nueva mestiza. En Oliva, Mario (comp.). Antología de lecturas del curso doctoral Decolonialidad y colonialismo. Universidad Nacional.

Carneiro, S. (2014). Ennegrecer el feminismo. Recuperado el 8 de junio de 2014 de http://ebookbrowsee.net/ennegrecerel-feminismo-sueli-carneiro-pdf-d43259738

Cesaire, A. (1955). Discursos sobre el colonialismo. En: Oliva, Mario (comp.). Antología de lecturas del curso doctoral Decolonialidad y colonialismo (pp. 50-154). Universidad Nacional.

Gómez, S. \& Grossfoguel, R. (2007). Prólogo. Giro decolonial, teoría crítica y pensamiento heterárquico (pp.9-21). Colombia: Siglo del Hombre Eds.

Hierro, Graciela (1998). Ética y feminismo. México: UNAM, Diversa.

Lagarde, Marcela (2003). Los cautiverios de las mujeres: madresposas, monjas, putas, presas y locas. México: UNAM. 
Lozano, B. (2010). Mujeres negras (sirvientas, putas y matronas): una aproximación a las mujeres negras de Colombia. Actualidad Étnica. Recuperado el 4 de abril de 2014 de http://www.revistas.una.ac.cr/index.php/tdna/article/viewFile/3720/3569

Lozano, B. (2009). Identidades desgarradas: mujeres negras de Colombia. Actualidad Étnica. Recuperado el 01 de abril de 2014 de www.hemeracomunicar.org.

Lugones, M. (2008). Colonialidad y género. Hacia un feminismo decolonial. En: Mignolo, W. (2008) (comp.). Género y descolonialidad (pp. 13-54). Buenos Aires: Del Signo.

Oquendo, L. (2009). Reflexiones para un discurso de género. Temas de Nuestra América (48). Costa Rica: EUNA.

Pérez, N. (2009). La participación política de las minorías étnicas en Costa Rica. De lo visible a lo invisible. Revista Casa de la Mujer (15). Recuperado el 10 de abril de 2014 de www.una.ac.cr/iem/revista/Revista\%2015.pdf
Perry, K. (2009). Rewriting Dispersal: Africana Gender Studies. S \& F Online. Recuperado el 4 de abril de 2014 de http:// sfonline.barnard.edu/africana/liking_01.htm

Pita, A., Grillo, M. (2013). Revistas culturales y redes intelectuales. Una aproximación metodológica. Temas de Nuestra América (54), 29, 177-194.

Pulgares, C. y Elena, M. (2008). La identidad de género, una reflexión desde las ciencias sociales. Revista Casa de la Mujer (14). Recuperado el 10 de abril de 2014 de www.una. ac.cr/iem/revista/Revista\%2014.pdf

Quijano, A. (2005). Colonialidad del poder, eurocentrismo y América Latina. En: Eduardo Lander (comp.). La colonialidad del saber: eurocentrismo y ciencias sociales. Perspectivas Latinoamericanas. La Habana: Editorial de Ciencias Sociales.

Teboho, M. (2001). Género y racismo. LOLA (16). Recuperado el 4 de abril 2014 de www.lolapress.org.iv/lo16.htm

Truth, S. (1851). Ain't I a Woman? The Feminist. Recuperado el 18 de junio de 2014 de http://www.feminist.com/ resources/artspeech/genwom/sojour.htm 